\title{
Implementing trauma-informed care through social innovation in child welfare residential treatment centres serving elementary school children
}

\section{Denise BREND ${ }^{1}$, Nicolas FRÉCHETTE ${ }^{2}$, Arnaud MILORD-NADON², Tim HARBINSON ${ }^{2}$, and Delphine COLLIN-VÉZINA ${ }^{3}$}

\footnotetext{
1 Psychoeducation Department, Université de Sherbrooke

2 Canadian not for profit organization Boscoville

3 School of Social Work, McGill University
}

Corresponding Author: Delphine Collin-Vézina, School of Social Work, McGill University, 3506 University st., room 321B, Montreal, Quebec, Canada H3A 2A7. Email: Delphine.collin-vezina@mcgill.ca.

\section{Abstract}

Objectives: This article presents the theoretical basis, initial deployment strategies, and resulting preliminary findings of a program implemented in residential treatment centres (RCs) in child welfare. "Program Penguin" aimed to help workers develop trauma-informed attitudes and implement trauma-informed practices, make the workplace more responsive to the well-being of RC workers, and reduce the use of restraints and seclusion among school-aged children in RCs.

Methods: Informed by the theories of complex trauma (National Child Traumatic Stress Network Complex Trauma Task Force, 2003), polyvicitimization (Finkelhor et al., 2007), Attachment, Self-Regulation and Competency (ARC; Blaustein \& Kinniburgh, 2018) and Positive Behavioural Interventions and Supports (PBIS; Sugai \& Horner, 2002), Program Penguin was developed and deployed using the social innovation approach (Fixsen et al. 2005). The key stages of social innovation will here be used to describe the implementation process.

Results: Changes in practices were observed, RC worker attitudes towards trauma-informed care were assessed and showed strong effects between multiple covariables. RC worker support needs were identified, and a reduction in the use of restraints and seclusions was shown. Key strategies towards the development and maintenance of buy-in and meaningful change in practices are also described.

Implications: Changes observed at all levels of this implementation suggest Programme Penguin is a promising approach, despite local issues that arose and the challenges inherent to program deployment within child protection settings. It appears a trauma-informed program using positive behavioural approaches and leveraging existing organizational strengths may impact intervention strategies, worker attitudes, and the use of restraints and seclusions against children in RCs.

Keywords: Residential treatment centres; complex trauma; trauma-informed care; implementation; social innovation. 
Implementing trauma-informed care through social innovation in child welfare residential treatment centres serving elementary school children

\section{Introduction}

The majority of children living in residential treatment centres under child protective or youth offender mandates have faced multiple forms of hardship, including abuse, separations from significant and caregiving relationships, abandonment or repeated displacements (Collin-Vézina et al., 2011; Hodgdon et al., 2013; Hummer et al., 2010). These traumatic experiences have consequences that can take the form of significant interpersonal difficulties, including aggressive and oppositional behaviour (Cook et al., 2005; D'Andrea et al., 2012). The complexity of how children with such challenges present in residential treatment centres can lead residential childcare workers to experience feelings of helplessness, stress, fatigue and a lack of understanding (Bloom, 2005; Geoffrion \& Ouellet, 2013), and increase the risk of interventions aimed at behavioural symptoms rather than root causes (Becker-Blease, 2017; Hodgdon et al., 2013). However, addressing challenging behaviours without a sensitivity to the potential influence of previous traumatic experiences can lead to post-traumatic stress among children in residential treatment centres (Ryan et al., 2006). Trauma-informed care (TIC) has been proposed as a means to create the secure relational contexts children need to overcome the impacts of traumatic experience (Bloom, 2005; Milne \& Collin-Vézina, 2015; Plumb et al., 2016).

\section{Complex trauma exposure and polyvictimization: Prevalence, severity, and consequences}

In the early 1990s, research on children who were chronically exposed to maltreatment showed that the diagnostic lens of post-traumatic stress disorder (PTSD) was inadequate to capture the complexity of their clinical portraits, and only partially reflected the negative aftereffects of their experiences (Milot et al., 2018b; Spinazzola et al., 2005). Researchers thus elaborated the concept of complex trauma based on criteria that are distinct from those of PTSD:

a) The child's exposure to traumatic experiences (such as abuse, neglect, violence including other potentially developmentally harmful experiences such as war or community violence) is repetitive and chronic;

b) These experiences are perpetrated in the context of caregiving relationships;

c) These experiences occur during vulnerable developmental periods (cognitively, psychologically and biologically) when the child has few coherent or effective strategies with which to respond (Cook et al., 2005; Milot et al., 2018a; van der Kolk, 2003).

Research has demonstrated that the total load of all exposures to potentially traumatic experiences, termed polyvictimization, can also contribute to post-traumatic stress among children (Turner et al., 2010). From here, complex trauma will be used as an umbrella term that includes polyvictimization.

Children placed in residential treatment centres show elevated prevalence rates and severity of exposure to potentially traumatic experiences. Indeed, whether in the Midwestern United States (Brady \& Caraway, 2002) or Québec, Canada (Collin-Vézina et al., 2011) the majority of children placed in residential treatment centres were reported to youth protective services because of maltreatment such as negligence, exposure to domestic violence, or physical, sexual or psychological abuse. Further, by adolescence only $2 \%$ of girls and $3 \%$ of boys placed in residential treatment centres under youth justice mandates had no reported adverse childhood experiences (Baglivio \& Epps, 2016). In terms of severity, Greeson and colleagues' study (2011) of 2,251 American children in the Child Welfare System showed that more than $70.4 \%$ of the sample had had two types of traumatic experiences, while $11.7 \%$ had suffered all five types of maltreatment measured. Collin-Vézina and colleagues' study (2011) of 53 adolescents in residential treatment centre showed that approximately $76 \%$ of the children had had more than two types of traumatic experiences and approximately $19 \%$ had experienced all five types. While Brady and Caraway (2002) studied different types of traumatic experiences, they reported similar results in their study of 41 children aged 6 to 12 living in residential treatment centres. The authors noted that nearly $87.8 \%$ of their sample had had at least two traumatic experiences, and $10.5 \%$ had experienced five types of maltreatment. The rates and amounts of traumatic experience among children placed in residential treatment centres are staggering (Fischer et al., 2016; Pane Seifert et al., 2015).

Multiple studies have demonstrated an array of negative consequences on multiple developmental areas linked to repeated exposure to traumatic experiences (Cook et al., 2005; Gregorowski \& Seedat, 2013). These effects can include reduced volume of the prefrontal cortex, amygdala, and hippocampus (van der Kolk, 2003); significant impairments in executive functioning (Kavanaugh et al., 2017; Perry, 2007); insecure attachment (Pearlman \& Courtois, 2005); difficulty expressing and identifying emotions (Pollak et al., 2000); difficulty with impulse control (Cook et al., 2005); dissociation (Collin-Vézina et al., 2011); behavioural issues (Benjet et al., 2010); and a negative self-image (Kim \& Cicchetti, 2006). Children who had experienced several forms of maltreatment showed a greater number of symptoms 
(Kisiel et al., 2009) and were more likely to meet clinical thresholds for conditions such as depression, PTSD, and dissociation (Collin-Vézina et al., 2011). Indeed, children living in residential treatment centres have been shown to have greater functional impairment than those who do not live in residential treatment centres (Briggs et al., 2012; Ko et al., 2008).

\section{Residential treatment centres \& trauma-informed care}

The purpose of this article is to present the theoretical underpinnings, implementation strategies, and preliminary observations related to Program Penguin, which aimed to improve residential treatment centre practices within child protection services. There was a pressing need to address practices in residential treatment centres. The 2013-2016 statistics for Québec's Integrated (University) Health and Social Services centre network showed that the use of restraint measures was continuously increasing (Noël et al., 2017). Restraints (by physical force or chemical substance) and seclusion (or isolation), as a means of control, can be used only in exceptional circumstances and only to prevent a person from inflicting harm upon themselves or others (Légis Québec, 2020). Although these practices are effective in reducing risks in some circumstances, negative effects can occur, including harm to helping relationships, increases in antisocial behaviours (Oehlberg, 2008; Sugai \& Horner, 2002), and the creation of additional traumatic triggers for children (Bloom, 2005). Current statistics suggest that residential childcare workers are increasingly unable to calm children before potentially harsh reactive measures are necessary (Hodgdon et al., 2013). It may be that a lack of specialized knowledge and training about the impacts of traumatic experiences on children, exacerbated by the stress and fatigue endemic in residential treatment centre work (Bloom, 2005), result in "reactive" or "controlling" interventions such as restraints and seclusion (LeBel et al., 2010; Roy et al., 2019). Residential childcare workers, their supervisors and managers require support to be the constantly present, caring adults shown to facilitate child development in the wake of traumatic experience (Blaustein \& Kinniburgh, 2018; Brend \& Sprang, 2020).

TIC proposes a new way of conceptualizing services provided to children impacted by complex trauma. The usual way of understanding and intervening with this clientele is transformed from treating a "disorder" or "illness" to interpreting children's behaviour as adaptive survival responses to their traumatic experiences (Oehlberg, 2008). It centres on skill acquisition and relationship management (Hansberry, 2016) and grounds interventions in collaboration and understanding of the traumatic roots of challenging behaviours. Given their role as caregivers, residential childcare workers are ideally placed to provide the necessary conditions for these children to overcome the impacts of their traumatic life experiences (Bryson et al., 2017; Geoffrion \& Ouellet, 2013; Tidwell, 2008). The introduction of TIC into residential treatment centres presents an opportunity to better leverage existing caregiving roles to address the effects of child trauma.

TIC offers strategies to integrate prevention within organizational functioning. For example, strategies to avoid reactivating children's trauma-related stress and protect residential childcare workers from secondary traumatic stress are proposed at the organizational level (Bloom, 2005; Elliott et al., 2005). This demonstrates how trauma-informed organizations are responsive to both the well-being of professionals and the children they serve. TIC is indicated for both children in residential treatment centre placement and the professionals who care for them (Brend \& Sprang, 2020). For the implementation of TIC to be successful, organizations need to institute policies, procedures and practices that make their setting safe and promote positive interactions with children (Becker-Blease, 2017; Bryson et al., 2017; Gregorowski \& Seedat, 2013; Jennings, 2004; Plumb et al., 2016). Protecting residential childcare workers promotes their capacity to be attuned to the needs of the children in their care, including secure caregiving relationships with emotionally regulated adults (Bloom, 2005). TIC approaches policy and practice with an "awareness of the prevalence of trauma, understanding the impact of trauma, and commitment to incorporating those understandings in policy, procedure, and practice" (Yatchmenoff et al., 2017, p. 167).

\section{Program PENGUIN}

Programme Pingouin [Program Penguin] was born out of a collaboration between Boscoville (a non-profit organization promoting the well-being of children and youth) and the Social Responses to Complex Trauma Research Group at McGill University. It is a trauma-informed program developed specifically to respond to the needs of residential treatment centres serving children aged 6 to 12. Deployed in the province of Québec, Canada, this program aimed to help workers develop trauma-informed attitudes and implement trauma-informed practices, make the workplace more responsive to the well-being of residential childcare workers, and reduce the use of restraints and seclusions among school-aged children in residential treatment centres. Program Penguin was developed and 
deployed using social innovation approach. This way of working puts a strong emphasis on the co-construction of innovative practices and aims to build upon pre-existing strengths within organizations. Supporting organizations as they moved through the implementation of Program Penguin was a key strategy employed to promote lasting cultural change (Fixsen et al., 2005).

\section{The theoretical foundations of program PENGUIN}

Four distinct yet overlapping knowledge bases were tapped to bring Program Penguin together. The first, complex trauma, set the stage for the residential treatment centre teams to understand why this innovative approach was necessary and to explain why it would benefit them and the children in their care. The second, the Attachment, Self-Regulation and Competency (ARC) framework, made clearer links between the impacts of complex trauma and what to do to help impacted children (i.e. TIC). The third, the Positive Behavioural Interventions \& Support (PBIS) framework offered further guidance on the specific types of intervention and programming proven to improve behavioural outcomes for children and youth in institutional settings. Finally, the fourth, social innovation, offered guidance to the implementation team on how best to work with the diverse residential treatment centre teams to promote scalable, sustainable local programs with high staff buy-in and a high possibility of holistic organizational transformation.

\section{Complex Trauma}

Understanding complex trauma, its prevalence among children in residential treatment centres, and how best to respond therapeutically to the impairments and dysfunction that can result from these experiences is foundational to this program. Training full residential treatment centre teams (e.g., managers, workers, clinical supports) allowed a shared language and vision regarding child behaviour, and a mutual sensitivity to the effects of some interventions on trauma reactivation (Bryson et al., 2017; Chafouleas et al., 2016; Dorado et al., 2016). In Program Penguin, all staff received awareness training to recognize the neurological and biological consequences of complex trauma. Residential treatment centre teams were given five additional one-day trainings that guided the transformation or confirmation of existing organizational practices. The clinical supervisors and unit managers received supplementary training and support activities to transfer the knowledge base from the implementation team to key individuals within each site.

$A R C$

The ARC framework (Blaustein \& Kinniburgh, 2018) was drawn upon to inform how TIC theory is translated into practice. ARC describes how to prevent behaviour problems and, when prevention is not possible, how to intervene with a focus on the causes of behaviours - rather than seeking to modify or extinguish them. Changing the focus of interventions with children in residential treatment centres who are emotionally dysregulated can also assist residential childcare workers to empathize with the dysregulated child, and to identify and deploy strategies to soothe them. ARC conceptualizes how children can recover from the impacts of complex trauma, assists practitioners to reduce the use of interventions that risk reactivating children's trauma responses, and places emphasis on supporting residential treatment centre workers in this demanding work to promote their capacity to stay attuned to the children in their care while preventing the potential for harmful impacts, such as secondary traumatic stress (Blaustein \& Kinniburgh, 2018). ARC interventions aim to develop children's self and relational skills and equip care systems and workers with adaptive responses to the developmental aftereffects of complex trauma. This theoretical framework draws on theories of resilience, attachment, neurobiology, complex trauma, and child development to foster evidencebased secure day-to-day interactions with children and youth (Hodgdon et al., 2013; Lawson \& Quinn, 2013). The ARC model is currently deployed in many settings and is recognized as a promising practice by the National Child Traumatic Stress and the Substance Abuse and Mental Health Service Administration. Outcome studies show a decrease in symptoms linked to post-traumatic stress, a decrease in use of restraint and seclusion measures (Hodgdon et al., 2013), and a decrease in externalized and internalized behavioural problems (Hodgdon et al., 2013; Arvidson et al., 2011).

PBIS

The PBIS framework integrates strategies shown to be effective in preventing challenging or potentially harmful behaviours and improving social skills through a preventive and proactive approach. Professionals are guided to implement strategies focussed on meeting youth needs using a structured approach to service delivery (Sugai \& Horner, 2002). PBIS creates an environment where children are shown the expectations of their behaviour and guided to achieve those expectations in a supportive and positive manner. Practices such as explicit teaching of expected behaviours, reinforcement of said behaviours, and tailored strategies to manage behaviour gaps are promoted (Sugai 
Implementing trauma-informed care through social innovation in child welfare residential treatment centres serving elementary school children

\& Horner, 2006). PBIS programs incorporate the collection of on-site data, both to document implementation and to assess intervention effects. In Program Penguin this site-specific use of data guided residential childcare workers by demonstrating what was working and what was not, so interventions could be suitably adjusted. As a result of the effectiveness PBIS has shown in the American school system, several states have started to widen its deployment from schools into residential settings (Flower et al., 2011). Outcome studies of PBIS in young offenders' services and alternative schools are promising. A 73\% decrease in the use of restraints and seclusion measures over a 15-month period (Sidana, 2006) and a significant decrease in behavioural problems (Simonsen \& Sugai, 2013) have been reported in those settings.

\section{Social Innovation}

Program Penguin was developed and implemented through social innovation. Social innovation is defined as an initiative, program, or project "that challenges and over time contributes to changing the defining routines, resources and authority flows or beliefs of the broader social system in which it is introduced" (Westley \& Laban, 2015, p. 5). The purpose of social innovation is to achieve lasting transformation through methods that include people with lived experience of the challenge being addressed and allows for the process of change to be scaled up to respond to the breadth of the social problem of concern (Surman, 2018). This applied strategy is inclusive of diverse voices and perspectives and seeks to attack root causes by co-constructing solutions through collaborative innovation. Surman (2018) proposed four nonlinear stages through which social innovation projects move towards completion: ideation, invention, adoption, and impact. These stages are effective at describing the progression of Program Penguin.

Ideation. This stage begins when an innovator intentionally starts a process to bring about change to solve a social issue. Program Penguin began when multiple innovators converged to pool their efforts to improve the lived reality and outcomes for children in residential treatment centres. Boscoville brought their knowledge accrued through promoting youth well-being through social innovation and PBIS and the Social Responses to Complex Trauma research team, under Delphine Collin-Vézina, brought their knowledge accrued through the implementation of an ARCinformed program in residential treatment centres throughout Québec. Through sustained work over months and in consultation with the partnering residential treatment centres in the pilot project (Estrie, Montérégie, Bas-St-Laurent, and Abitibi-Témiscamingue) Program Penguin was formed. Figure 1 shows how the different knowledge bases came together to form an innovative, tiered framework specific to the residential treatment centre context. Like an iceberg, what is at the bottom - or underwater - makes the biggest impact on how things move. Program Penguin is anchored by the knowledge and capacities brought into the helping relationship by professionals. Above the water line, we see three tiers representing the intervention structure used in complement with data collected on-site in the day-to-day programming. The base of this triangle represents competency, emotion regulation, routines and rhythms. These elements of Program Penguin are in place for all children at all times and represent optimal conditions for many children placed in residential treatment centres. The second tier represents the strategies employed for children who are at a higher risk of impairment or dysfunction (case studies, preventative skills training, and support in small groups), or who are not adequately soothed by the strategies represented in the first tier. In the third tier, individual interventions and referrals are proposed for the most vulnerable children or those who are not responding to the interventions represented in the first two tiers.

Invention. In this stage, the new process or approach is introduced as a novel strategy to create the desired change. It is a stage of trial and error and experimentation. Program Penguin introduced a series of novel guiding principles and methods. First, the imperative was to train the entire team in each residential treatment centre. Second, it was to create safe (i.e. secure, predictable, coherent) environments for both the children and the residential treatment centre team. This included, for example, how training was offered. Staff were not quizzed or put on the spot in training. Attending to the well-being of residential treatment centre team members was a priority at every level of implementation. Training was designed to buffer upsetting content by making the context of traumatic experiences explicit and training the teams on the potential for secondary traumatic stress, and what to do about it. A strategy for decision-making based on data was introduced and incorporated in the implementation, proposed interventions, and problem resolution strategies. On-site TIC expertise was developed to transfer knowledge from the implementation team to the residential treatment centres, making the program more independently sustainable. The structured interventions introduced in the training were further co-developed with each site to ensure they were relevant to local needs while maintaining efficacy. Finally, throughout the implementations multi-site exchanges were held to allow the different residential treatment centre settings to learn from each other about effective strategies and problems 
encountered throughout the province. In this way, different regions were able to coordinate with each other to further promote the co-development of their programs.

Figure 1. The Program Penguin Model

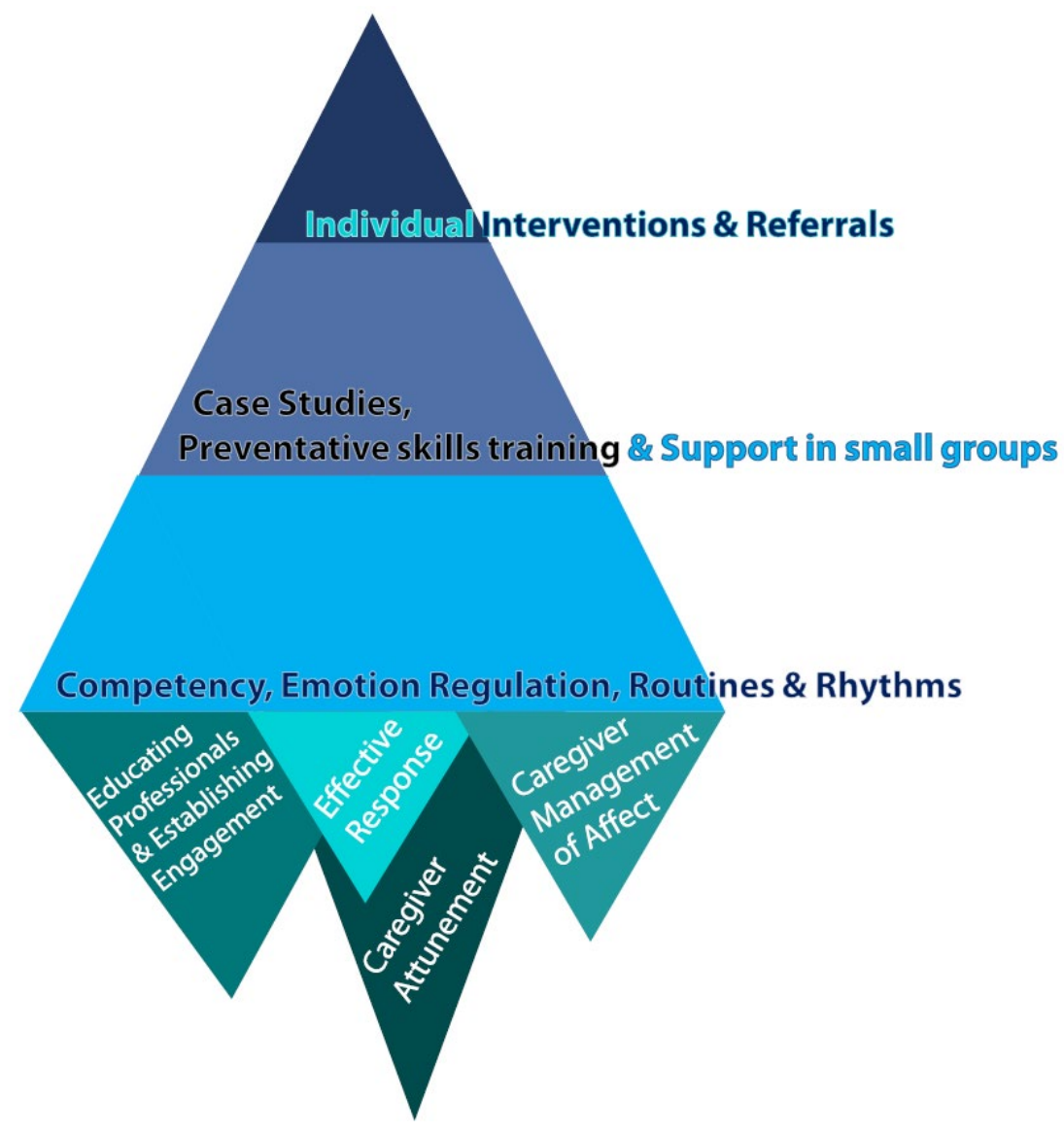

Adoption. This stage refers to the scaling up and replication of the social innovation effort. In 2018, the Program Penguin pilot project was launched in five residential treatment centres in four different regions of Québec. Currently, the program is running in nine units across eight regions. Further, due to a demand from the original five residential treatment centres and new residential treatment centres who learned about the pilot project, an adolescent version of Program Penguin has also been developed (Program Polaris) and is currently launched in fifteen residential treatment centres over six Québec territories. To generate Program Polaris, only the knowledge base of Program Penguin was adapted, to reflect the realities and needs of adolescents and the residential treatment centre professionals serving them. Between these two programs, 44\% of Québec's Integrated (University) Health and Social Services centre network has at least one implementation underway. Adapting practices to different regions and different teams was key to residential treatment centre team engagement and motivation. Since residential treatment centres differ greatly from one region to another in terms of staff, clinical support, and financial resources, it was important that practices be adapted to each setting. By design, each residential treatment centre team had the freedom to identify their core values, adapt the themes used, and engage their creativity in defining how the elements of the program were presented to the children and youth. The motivation that these implementations have inspired is exemplified by the residential childcare workers in one setting volunteering to repaint their entire unit in their chosen theme (a colourful nature theme with cartoon animals). Making space for the vision of the residential treatment centre teams to be woven throughout the program mobilized and unified them around the challenging transition they were called on to make in their perspectives and practices.

Impact. This stage represents a measurable difference that the social innovation has produced - how the system or social problem has been changed for the better. Before and during the implementation of Program Penguin 
several types of data were collected. First, the Boscoville development agents conducted individual interviews and focus groups with all of the professionals involved in evaluating the implantation on an ongoing basis. Agents observed increases in the use of positive, trauma-informed interventions although some residential childcare workers interpreted the new intervention style as "lax," or "without rules or limits." Through training, on-site coaching, case studies, implementation committees, and clinical supervision, the Boscoville development agents observed teams applying the Penguin approach and developing intervention strategies to replace the use of ineffective limits or consequences. For example, several units created calming rooms and residential childcare workers reported that having these rooms available lead to a decrease in the use of restraints and seclusion as well as to a new perspective on the use time-outs (a tool for calming rather than punishing a child).

Residential treatment centre team member attitudes were measured using the attitudes related to traumainformed care (ARTIC-35) scale (Baker et al., 2016). Strong effects between team member characteristics and attitudes related to trauma-informed care measured by the ARTIC-35 were found. Team member attitudes were impacted by: (a) the ages of the clients they served (children or youth), (b) the legal mandate under which their clients were placed (child protection or young offenders), (c) the professional role they occupied (residential childcare worker or management) and their level of education. These effects suggested that TIC implementation must be tailored to account for differences in TIC attitudes pre-training, including the clientele served, the mandate under which they are receiving child welfare services, the educational background of the workers, and the workers' current positions in the child welfare system (Collin-Vézina et al., 2020). Interview data was collected in three waves pre, mid and post pilot project implementation using the Secure Base Interview (Schofield \& Beek, 2018). The final section of this interview asks about sources of support for the professionals in residential treatment centres. An analysis of that data from the preimplementation interviews indicated the value of collegial support and the need for adequate resources such as: having enough time to spend with their assigned youth, effective training for all staff members, adequate ratios of professionals to youth on the floor, reliable and routine access to unit managers and clinical supervision, regular team meetings, and breaks throughout their shift (Brend \& Collin-Vézina, 2020). Finally, there has been an analysis of provincial administrative restraints and seclusion (SR) data. SRs occurring in residential treatment centres prior to and 12 months following the implementation of Program Penguin and the concurrent ARC-informed staff training implementations were analyzed, showing an increase of SRs within the first two months of implementation followed by a steady decrease thereafter (Matte-Landry \& Collin-Vézina, 2019). Program Penguin and Program Polaris have shown evidence that changes have resulted in residential treatment centre team attitudes, practices and outcomes for children and youth.

\section{Limitations}

Implementing programs in the field through social innovation is challenging and requires a great deal of flexibility on the part of an implementation team. The flexibility inherent to social innovation runs counter to the standardization required in many research methods. It could therefore be argued that due to across-site differences, our findings lack some generalizability. Second, the challenging context of residential treatment centre worker turnover had many impacts on our implementations, where in one site the implementation had to be completely re-started when all of the original participants had left. We failed to anticipate the need to train new staff on an as-needed basis and find ways to onboard them as the implementation was underway. Third, we developed a novel process for the collection of data about day-to-day youth behavioural issues. This tool proved challenging to implement largely due to daily time constraints faced by residential treatment centre workers. Strategies to improve this process must be identified to ensure interventions are data driven. Finally, these programs were implemented within the whole system of each residential treatment centre; however, without implementation at higher levels, unit managers had limited capacity to make necessary changes (i.e. to budgets or allocation of staffing). As our TIC initiative occurred downstream within a larger system, we were limited in how far transformative practices could be advanced.

\section{Future Considerations}

First, the inclusion of worker-level data (turnover, sick leaves, exit interviews, etc.) would be a valuable addition to TIC implementation. Little is known about the possible impacts of TIC programs on reducing turnover and intent to leave among residential treatment centre professionals and these are critical considerations towards creating secure and stable helping relationships for children in care. Second, while TIC calls for the inclusion of social oppression in program development, greater emphasis on including intersecting perspectives from equity seeking groups in 
program development is indicated. Further, Indigenous and children of colour are overrepresented in systems of care making voices from their communities critical towards the development of effective TIC programming. Third, identifying strategies to improve coordination with professionals offering services to the children and youth external to residential treatment centres (psychologists, occupational therapists) is important towards assuring consistency in the therapeutic approaches being used with each individual child and youth. Finally, systematically assessing the potentially harmful impacts to residential treatment centre professionals (e.g. secondary traumatic stress, moral distress, burnout) and identifying the most effective strategies to promote their resilience and efficacy would also be a valuable direction to take future research efforts.

\section{Conclusion}

The implementation of a TIC program into residential treatment centres requires a reappraisal of every aspect of practice, from the philosophies that ground attitudes towards children and youth in placement to the behavioural expectations related to each moment in their routine. Our implementation strategy delivering trauma-informed care through social innovation has succeeded in motivating residential treatment centre professionals to change their practices and suggest that delivering a TIC program through social innovation is a promising approach. We found workers' needs and attitudes, intervention strategies, and the use of restraints and seclusions were altered following Program Penguin. These changes occurred despite local issues that arose and the challenges inherent in program deployment within child protective settings. Further, our understanding about the factors that result in positive changes for children and youth in care and the professionals caring for them have been enriched. Program Penguin will continue to evolve in response to the new evidence arising from ongoing inquiries into the effectiveness of this novel approach to the implementation of trauma-informed care. We hope to continue to co-develop Programs Penguin and Polaris towards improving interventions for children, clinical support for workers, and promoting the TIC approach for all of the services connected with children and youth.

\section{Funding}

Denise Brend acknowledges postdoctoral funding support through the MITACS Accélération program (IT10444).

\section{Conflict of interest}

The authors have no conflict of interest to disclose.

\section{References}

Arvidson, J., Kinniburgh, K., Howard, K., Spinazzola, J., Strothers, H., Evans, M., Andres, B., Cohen, C., \& Blaustein, M. (2011). Treatment of complex trauma in young children: Developmental and cultural considerations in application of the ARC intervention model. Journal of Child \& Adolescent Trauma, 4(1), 34-51. https://doi.org/10.1080/19361521.2011.545046

Baglivio, M., \& Epps, N. (2016). The interrelatedness of adverse childhood experiences among high-risk juvenile offenders. Youth Violence and Juvenile Justice, 14(3), 179-198. https://doi.org/10.1177/1541204014566286

Baker, C., Brown, S., Wilcox, P., Overstreet, S., \& Arora, P. (2016). Development and psychometric evaluation of the attitudes related to trauma-informed care (ARTIC) scale. School Mental Health, 8(1), 61-76. https://doi.org/10.1007/s12310-015-9161-0

Becker-Blease, K. (2017). As the world becomes trauma-informed, work to do. Journal of Trauma \& Dissociation, 18(2), 131-138. https://doi.org/10.1080/15299732.2017.1253401

Benjet, C., Borges, G., \& Medina-Mora, M. (2010). Chronic childhood adversity and onset of psychopathology during three life stages: Childhood, adolescence and adulthood. Journal of Psychiatric Research, 44(11), $732-740$. https://doi.org/10.1016/j.jpsychires.2010.01.004

Blaustein, M., \& Kinniburgh, K. (2018). Treating traumatic stress in children and adolescents: How to foster resilience through attachment, self-regulation, and competency (2nd ed.). Guilford Publications.

Bloom, S. (2005). The sanctuary model of organizational change for children's residential treatment. Therapeutic Community: The International Journal for Therapeutic and Supportive Organizations, 26(1), 65-81.

Brady, K., \& Caraway, S. (2002). Home away from home: factors associated with current functioning in children living in a residential treatment setting. Child Abuse \& Neglect, 26(11), 1149-1163. https://doi.org/10.1016/S0145-2134(02)00389-7 
Brend, D., \& Collin-Vézina, D. (2020). Effective and necessary supports for residential childcare workers in child welfare practice [Manuscript in preparation]. McGill University \& Université de Sherbrooke.

Brend, D. M., \& Sprang, G. (2020). Trauma-informed care in child welfare: An imperative for residential childcare workers. International Journal of Child \& Adolescent Resilience, 71 1), 154-165.

Briggs, E., Greeson, J., Layne, C., Fairbank, J., Knoverek, A., \& Pynoos, R. (2012). Trauma exposure, psychosocial functioning, and treatment needs of youth in residential care: Preliminary findings from the NCTSN core data set. Journal of Child \& Adolescent Trauma, 5(1), 1-15. https://doi.org/10.1080/19361521.2012.646413

Bryson, S., Gauvin, E., Jamieson, A., Rathgeber, M., Faulkner-Gibson, L., Bell, S., Davidson, J., Russel, J., \& Burke, S. (2017). What are effective strategies for implementing trauma-informed care in youth inpatient psychiatric and residential treatment settings? A realist systematic review. International Journal of Mental Health Systems, 11(1), 36. https://doi.org/10.1186/s13033-017-01373

Chafouleas, S., Johnson, A., Overstreet, S., \& Santos, N. (2016). Toward a blueprint for trauma-informed service delivery in schools. School Mental Health, 8(1), 144-162. https://doi.org/10.1007/s12310-015-9166-8

Collin-Vézina, D., Brend, D., Black, K., Beeman, I., \& Brown, S. (2020). Impacts of child welfare worker and clientele characteristics on attitudes towards trauma informed-care [Manuscript submitted for publication]. McGill University.

Collin-Vézina, D., Coleman, K., Milne, L., Sell, J., \& Daigneault, I. (2011). Trauma experiences, maltreatment-related impairments, and resilience among child welfare youth in residential care. International Journal of Mental Health and Addiction, 9(5), $577-589$. https://doi.org/10.1007/s11469-011-9323-8

Cook, A., Spinazzola, J., Ford, J., Lanktree, C., Blaustein, M., Cloitre, M., DeRosa, R., Hubbard, R., Kagan, R., Liautaud, J., Mallah, K., Olafson, E., \& van der Kolk, B. (2005). Complex trauma in children and adolescents. Psychiatric Annals, 35(5), $390-398$. https://doi.org/10.3928/00485713-20050501-05

D'Andrea, W., Ford, J., Stolbach, B., Spinazzola, J., \& van der Kolk, B. (2012). Understanding interpersonal trauma in children: Why we need a developmentally appropriate trauma diagnosis. American Journal of Orthopsychiatry, 82(2), 187. https://doi.org/10.1111/j.1939-0025.2012.01154.x

Dorado, J., Martinez, M., McArthur, L., \& Leibovitz, T. (2016). Healthy environments and response to trauma in schools (HEARTS): A whole-school, multi-level, prevention and intervention program for creating trauma-informed, safe and supportive schools. School Mental Health, 8(1), 163-176. https://doi.org/10.1007/s12310-016-9177-0

Elliott, D., Bjelajac, P., Fallot, R., Markoff, L., \& Reed, B. (2005). Trauma-informed or trauma-denied: principles and implementation of trauma-informed services for women. Journal of Community Psychology, 33(4), 461-477. https://doi.org/10.1002/jcop.20063

Finkelhor, D., Ormrod, R., \& Turner, H. (2007). Poly-victimization: A neglected component in child victimization. Child Abuse \& Neglect, 31(1), 7-26. https://doi.org/10.1016/j.chiabu.2006.06.008

Fischer, S., Dölitzsch, C., Schmeck, K., Fegert, J., \& Schmid, M. (2016). Interpersonal trauma and associated psychopathology in girls and boys living in residential care. Children and Youth Services Review, 67, $203-211$. https://doi.org/10.1016/j.childyouth.2016.06.013

Fixsen, D., Naoom, S., Blase, K., Friedman, R., \& Wallace, F. (2005). Implementation research: A synthesis of the literature. University of South Florida, Louis de la Parte Florida Mental Health Institute, The National Implementation Research Network (FMHI Publication \#231). https://fpg.unc.edu/sites/fpg.unc.edu/files/resources/reports-and-policy-briefs/NIRN-MonographFull-012005.pdf

Flower, A., McDaniel, S., \& Jolivette, K. (2011). A literature review of research quality and effective practices in alternative education settings. Education and Treatment of Children, 34(4), 489-510. https://www.jstor.org/stable/42900130

Geoffrion, S., \& Ouellet, F. (2013). Quand la réadaptation blesse? Éducateurs victimes de violence. Criminologie, 46(2), 263-289. . https://doi.org/10.7202/1020996ar

Greeson, J., Briggs, E., Kisiel, C., Layne, C., Ake III, G., Ko, S., Gerrity, E., Steinberg, A., Howard, M., \& Pynoos, R. (2011). Complex trauma and mental health in children and adolescents placed in foster care: Findings from the National Child Traumatic Stress Network. Child Welfare, 9066), 91.

Gregorowski, C., \& Seedat, S. (2013). Addressing childhood trauma in a developmental context. Journal of Child \& Adolescent Mental Health, 25(2), 105-118. https://doi.org/10.2989/17280583.2013.795154

Hansberry, B. (2016). A practical introduction to restorative practice in schools: Theory, skills and guidance. Jessica Kingsley Publishers.

Hodgdon, H., Kinniburgh, K., Gabowitz, D., Blaustein, M., \& Spinazzola, J. (2013). Development and implementation of traumainformed programming in youth residential treatment centers using the ARC framework. Journal of Family Violence, 28(7), 679-692. https://doi.org/10.1007/s10896-013-9531-z

Hummer, V., Dollard, N., Robst, J., \& Armstrong, M. (2010). Innovations in implementation of trauma-informed care practices in youth residential treatment: A curriculum for organizational change. Child Welfare, 89(2), 79-95. 
Jennings, A. (2004). Models for developing trauma-informed behavioral health systems and trauma-specific services (Alexandria, VA: National Association of State Mental Health Program Directors, National Technical Assistance Center for State Mental Health Planning, Issue. https://www.theannainstitute.org/MDT2.pdf

Kavanaugh, B., Dupont-Frechette, J., Jerskey, B., \& Holler, K. (2017). Neurocognitive deficits in children and adolescents following maltreatment: Neurodevelopmental consequences and neuropsychological implications of traumatic stress. Applied Neuropsychology: Child, 6(1), 64-78. https://doi.org/10.1080/21622965.2015.1079712

Kim, J., \& Cicchetti, D. (2006). Longitudinal trajectories of self-system processes and depressive symptoms among maltreated and nonmaltreated children. Child Development, 7オ3), 624-639. https://doi.org/10.1111/j.1467-8624.2006.00894.x

Kisiel, C., Fehrenbach, T., Small, L., \& Lyons, J. (2009). Assessment of complex trauma exposure, responses, and service needs among children and adolescents in child welfare. Journal of Child \& Adolescent Trauma, 2(3), 143-160. https://doi.org/10.1080/19361520903120467

Ko, S., Ford, J., Kassam-Adams, N., Berkowitz, S., Wilson, C., Wong, M., Brymer, M., \& Layne, C. (2008). Creating trauma-informed systems: Child welfare, education, first responders, health care, juvenile justice. Professional Psychology: Research and Practice, 39(4), 396-404. https://doi.org/10.1037/0735-7028.39.4.396

Lawson, D., \& Quinn, J. (2013). Complex trauma in children and adolescents: Evidence-based practice in clinical settings. Journal of Clinical Psychology, 69(5), 497-509. https://doi.org/10.1002/jclp.21990

LeBel, J., Huckshorn, K., \& Caldwell, B. (2010). Restraint use in residential programs: Why are best practices ignored? Child Welfare, $89(2)$.

Légis Québec. (2020). Act respecting health services and social services. S-4.2, 118.1. http://legisquebec.gouv.qc.ca/fr/showdoc/cs/S4.2

Matte-Landry, A., \& Collin-Vézina, D. (2019). Patterns of change in restraints, seclusions and time-outs over the implementation of trauma-informed staff training programs in residential care for children and youth [Manuscript submitted for publication]. McGill University.

Milne, L., \& Collin-Vézina, D. (2015). Assessment of children and youth in child protective services out-of-home care: An overview of trauma measures. Psychology of Violence, 5(2), 122. https://doi.org/10.1037/a0037865

Milot, T., Collin-Vézina, D., \& Godbout, N. (2018a). Répercussions liées aux traumas complexes. In T. Milot, D. Collin-Vézina, \& N. Godbout (Eds.), Trauma complexe: Comprendre, évaluer et intervenir. Presses de l'Université du Québec.

Milot, T., Collin-Vézina, D., \& Godbout, N. (2018b). Trauma complexe : Comprendre, évaluer et intervenir. Presses de l'Université du Québec.

National Child Traumatic Stress Network Complex Trauma Task Force. (2003). Complex Trauma in Children and Adolescents [White paper]. https://www.nctsn.org/sites/default/files/resources/complex_trauma_in_children_and_adolescents.pdf

Noël, V., Papillon, S., \& Saint-Georges, C. (2017). Étude sur l'utilisation de l'isolement et de la contention au sein des missions réadaptation jeunesse des CISSS et CIUSSS du Québec, ainsi que dans certains établissements non fusionnés. https://www.cdpdj.qc.ca/Publications/Etude_isolement_contention.pdf

Oehlberg, B. (2008). Why schools need to be trauma informed. Trauma and Loss: Research and Interventions, 8(2), 12-15.

Pane Seifert, H., Farmer, E., Wagner, H., Maultsby, L., \& Burns, B. (2015). Patterns of maltreatment and diagnosis across levels of care in group homes. Child Abuse \& Neglect, 42, 72-83. https://doi.org/10.1016/j.chiabu.2014.12.008

Pearlman, L., \& Courtois, C. (2005). Clinical applications of the attachment framework: Relational treatment of complex trauma. Journal of Traumatic Stress, 18(5), 449-459. https://doi.org/10.1002/jts.20052

Perry, B. (2007). Stress, trauma and post-traumatic stress disorders in children: An introduction https://7079168e-705a-4dc7-be052218087aa989.filesusr.com/ugd/aa51c7_60c617d2160b417d9ee0f80e5ca8eaac.pdf

Plumb, J., Bush, K., \& Kersevich, S. (2016). Trauma-sensitive schools: An evidence-based approach. Schoo/ Social Work Journal, 40(2), 37-60.

Pollak, S., Cicchetti, D., Hornung, K., \& Reed, A. (2000). Recognizing emotion in faces: Developmental effects of child abuse and neglect. Developmental psychology, 36(5), 679-688. https://doi.org/10.1037//0012-1649.36.5.679

Roy, C., Castonguay, A., Fortin, M., Drolet, C., Franche-Choquette, G., Dumais, A., Lafortune, D., Bernard, P., \& Geoffrion, S. (2019). The use of restraint and seclusion in residential treatment care for youth: A systematic review of related factors and interventions. Trauma, Violence \& Abuse. Advance online publication. https://doi.org/10.1177/1524838019843196

Ryan, B., Bashant, J., \& Brooks, D. (2006). Protecting and supporting children in the child welfare system and the juvenile court. Juvenile and Family Court Journal, 571), 61-69. https://doi.org/10.1111/j.1755-6988.2006.tb00115.x

Schofield, G., \& Beek, M. (2018). Providing a secure base. University of East Anglia. https://www.uea.ac.uk/documents/3437903/5622491/THE+SECURE+BASE+INTERVIEW.pdf 
Sidana, A. (2006). PBIS in juvenile justice settings. The National Evaluation and Technical Assistance Center for the Education of Children and Youth Who are Neglected, Delinquent, or At-Risk. Retrieved May 11, 2007, from https://neglecteddelinquent.ed.gov/sites/default/files/PBISinJuvenileJusticeSettings.pdf

Simonsen, B., \& Sugai, G. (2013). PBIS in alternative education settings: Positive support for youth with high-risk behavior. Education and Treatment of Children, 36(3), 3-14. https://doi.org/10.1353/etc.2013.0030

Spinazzola, J., Blaustein, M., \& van der Kolk, B. (2005). Posttraumatic stress disorder treatment outcome research: The study of unrepresentative samples? Journal of Traumatic Stress, 18(5), 425-436. https://doi.org/10.1002/jts.20050

Sugai, G., \& Horner, R. (2002). The evolution of discipline practices: School-wide positive behavior supports. Child \& Family Behavior Therapy, 24(1-2), 23-50. https://doi.org/10.1300/J019v24n01_03

Surman, T. (2018). Unlocking Canadian social innovation. Centre for Social Innovation. https://socialinnovation.org/wpcontent/uploads/2018/12/Unlocking-Canadian-Social-Innovation-.pdf

Tidwell, W. (2008). Functional sssessment in residential treatment. Residential Treatment for Children \& Youth, 23(3-4), 37-60. https://doi.org/10.1080/08865710609512716

Turner, H., Finkelhor, D., \& Ormrod, R. (2010). Poly-victimization in a national sample of children and youth. American Journal of Preventive Medicine, 38(3), 323-330. https://doi.org/10.1016/j.amepre.2009.11.012

van der Kolk, B. (2003). The neurobiology of childhood trauma and abuse. Child and Adolescent Psychiatric Clinics, 12(2), $293-317$. https://doi.org/10.1016/S1056-4993(03)00003-8

Westley, F., \& Laban, S. (2015). Social innovation lab guide. Waterloo Institute for Social Inovation and Resilience. https://uwaterloo.ca/waterloo-institute-for-social-innovation-and-resilience/projects/social-innovation-lab-guide

Yatchmenoff, D., Sundborg, S., \& Davis, M. (2017). Implementing trauma-informed care: Recommendations on the process. Advances in Social Work, 18(1), 167-185. https://doi.org/10.18060/21311 